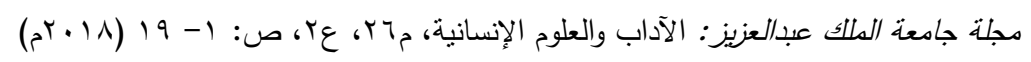

DOI:10.4197 / Art.26-2.1

وسطية العقيدة الإسلامية ومظاهرها في المجتمع السعودي

$$
\begin{aligned}
& \text { الاكتور محمد أمين الحق } \\
& \text { الأستاذ المشارك بقسم الدعوة والدراسات الإسالامبية }
\end{aligned}
$$

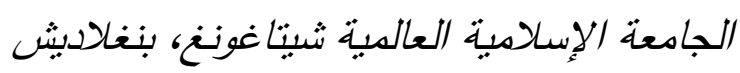

$$
\begin{aligned}
& \text { aminulhoque.iiuc@gmail.com }
\end{aligned}
$$

المستخلص: من خصائص الإسلام أنه دين وسط، لا إفراط فيه ولا تفريط، وهذه السمة تتسم في العقبدة والعبادة والأحكام والثريعة والأخلاق والمعاملة والسياسة والاقتصاد وما إلى ذلك من الأمور الأخرى، وفي

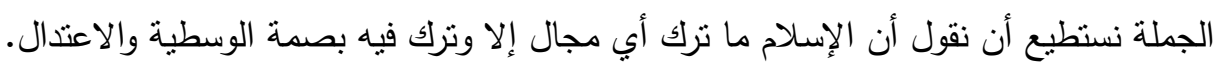

وهذا البحث تتاول مجال الوسطية في العقيدة الإسلامية ومظاهرها في المجتمع السعودي حيث أنه بين موقف المجتمع السعودي (العلماء وعامة الناس) من وسطية العقيدة الإسلامية، وقد تبين من خلال هذا البحث أن العقيدة الإسلامية تتميز بالوسطية والاعتدال والمجتمع السعودي أخذ هذه الميزة الرفيعة وسار عليها علما وعملا، فكانت المعاملة بها فيما بينهم وبين خالقهم وقاموا بتطبيق الوسطية أيضا في مراحل حياتهم، وذلك معتمدين على منهج الرسول - صلى الله عليه وسلم- والصحابة سرضوان اله تعالى عليهم أجمعين - وعلى السلف الصالحين من بعدهم من التابعين ومن تبعهم بإحسان إلى يوم الدين.

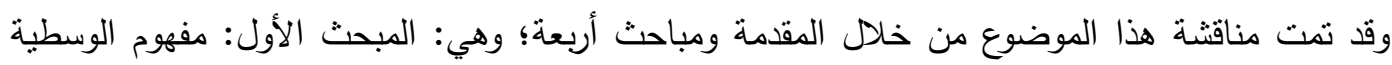
والعقيدة الإسلامية، والمبحث الثاني: الوسطية في العقيدة الإسلامية ومنهج المجتمع السعودي في ثلقي العقيدة، والمبحث الثالث: مظاهر وسطية العقيدة الإسلامية في المجتمع السعودي، والمبحث الرابع: موقف علماء السعودية من الدفاع عن العقيدة الإسلامية، وأخيرا انتهى البحث بالخاتمة، وذللك بذكر بعض الإسهائه النتائج

التي نوصل إليها الباحث من خلال البحث. من عنده

والسلام على النبي الأمين وعلى آله وصحبه أجمعين.

لقد وصف الله تعالى هذه الأمة بأنها أمة وسطا،

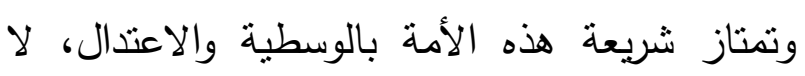

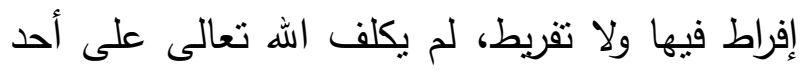

\section{المقدمة}

الحمد لله رب العالمين القائل في كتابه المبين: 

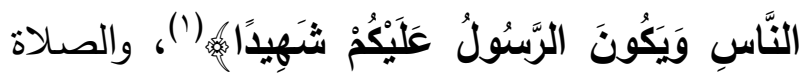


قال أبو بكر بن العربي: "كان من قبلنا من الأمم

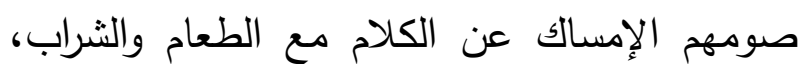

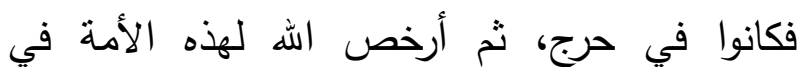

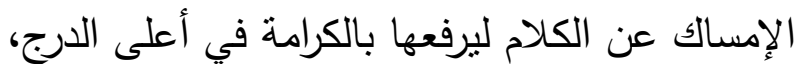

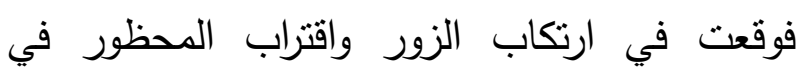

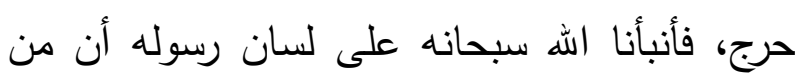
اقترب زوراً أو أتى من القول منكوراً، أن الهه سبحانه في غنى عن الإمساك عن طعامه وشرابه"( (^).

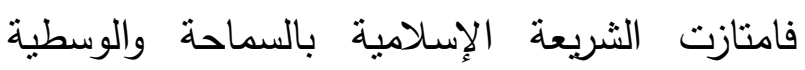

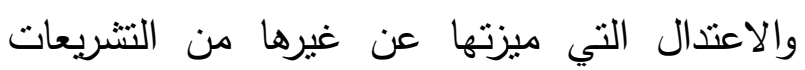
الأخرى، فتظهر وسطيتها في كل جانب من الجوانب البشرية، نظهر وسطيتها في عقيدتها، وعباداتها، ودعوتها، وأحكامها، وأخلاقها وسلوكها، ومعاملتها وعالها

$$
\text { أولا: أهمية الآخرين... }
$$

تبرز أهمية هذا الموضوع وأسباب اختياره من خلا لهل النقاط التالية: - النية

1- الحاجة إلى دراسة هذا الموضوع لكونه -في

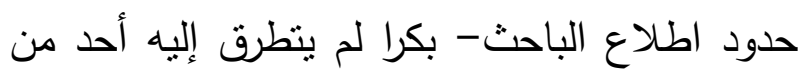

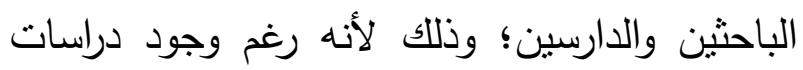
متعددة حول وسطية الإسلام في جوانب شتى في ولي لإنه الأيام الماضية إلا أنه لم يغطي الجانب الإنب الذي في يريد

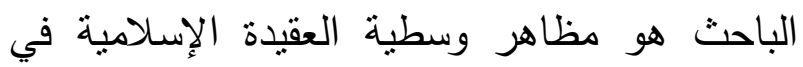
المجتمع السعودي. r- الدراسات حول موقف المجتمع السعودي من وسطية العقبدة الإسلامية، وذلك تحريا لكثف آثارها

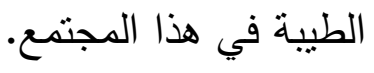

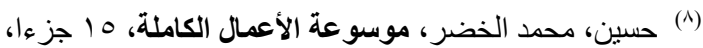

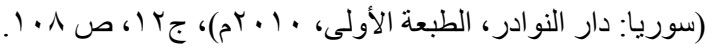

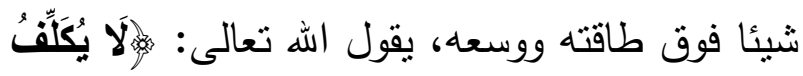

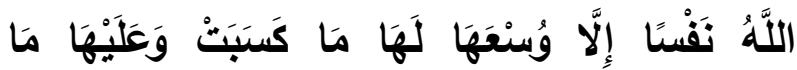

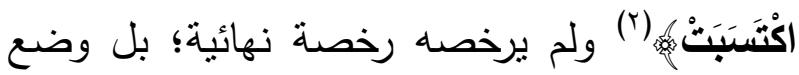

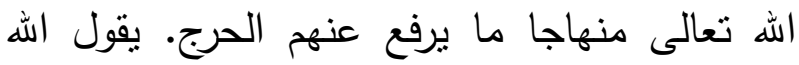

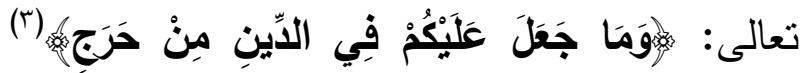

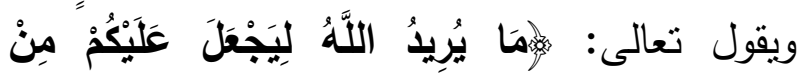
حَرَجِهُ. لو تطرقنا إلى التشريعات الماضية قبل الإسلام ليتضح أمامنا جليا بأن الأمم السابقة واجهت صعوبات عديدة في انباع أوامر الثارع، فمثنلا:

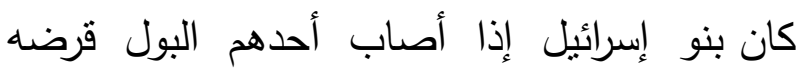

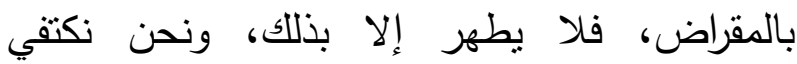
بغسله. (0) (ن) وكان اليهود إذا حاضت المرأة فيهم لم يؤاكلوها ولم

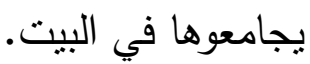
وكان في بني إسرائيل القصاص في القتلى ولم تكن فيهم الدية فخفف الله عنا بتشريع الدية فذللك قوله

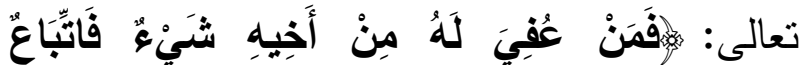

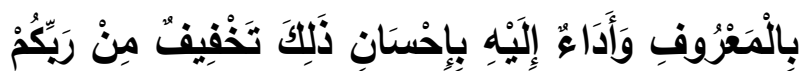

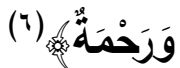
وقد كان الرجل من بني إسرائيل يذنب الذنب فيصبح

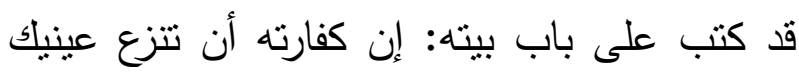
فينزعهما. في كن

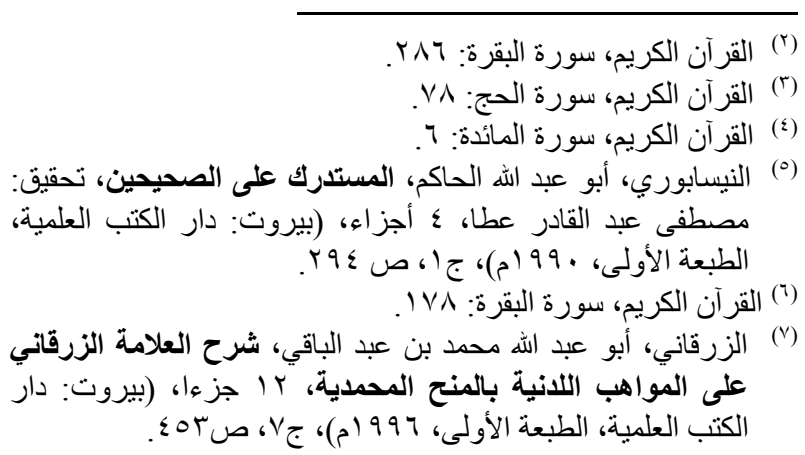


القبيلة بالوادي، والقاع، وما أثبهه، فخير الوادي وسطه، فيقال: هذا من وسط قومه، ومن وسط الوادي، وسرر الوادي، وسرارته، وسره، ومعناه كله من خير مكان فيه، فكذلك النبي صلى الله عليه وسلم من خير مكان في نسب العرب، وكذللك جُعلت أُمته أمة وسطاً، أي خياراً"('). "الوسطية تعني التوازن والاعتدال بين طرفي الغلو والتقصير، والإفراط والتفريط، فالوسطية منزلة بين طرفين كلاهما مذموم: فالثجاعة وسط بين الجبن والتهور ، والسخاء وسط بين التبذير والتقتير". (rا')

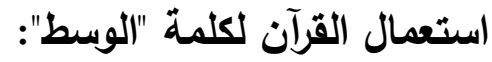
لو امعنا النظر في القرآن الكريم لوجدنا أنه استعمل كلمة الوسط بمعان ثثلاثة، وهي: العدل والخير والتوسط بين طرفي الإفراط والتقريط. وتثضح هذه المعاني الثلاثة جليا في الآيات القرآنية في مواضع خمسة:

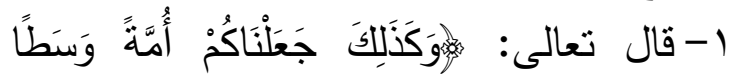

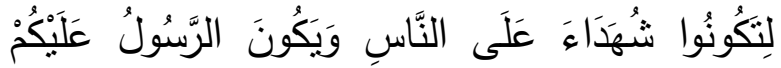

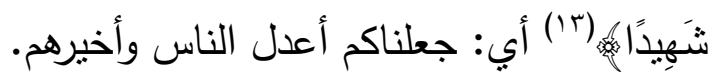

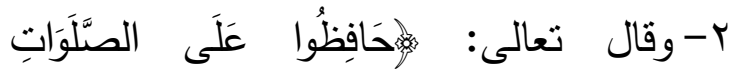

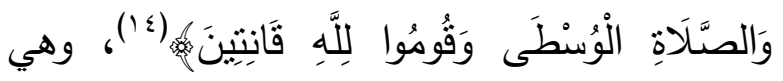
أفضل أوقات الصلاة عند المفسرين.

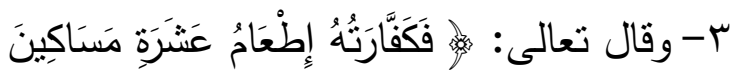

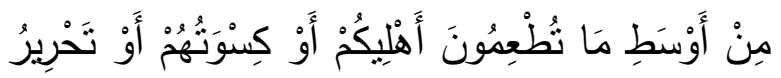

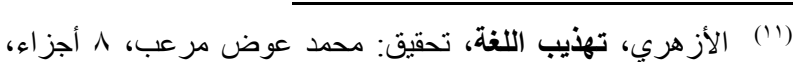

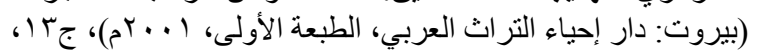

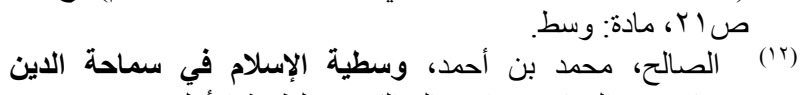

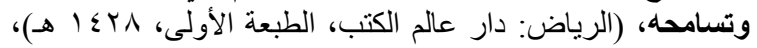
ص 9 گـ.

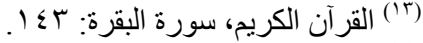

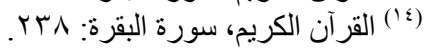

r-معرفة منهجهم في هذا الجانب وتحليله في ضوء القرآن والسنة. ثانيا: أهداف البحث: ان والهنه إن الباحث يسعى من خلال هذا البحث المتواضع إلى تحقيق الأهداف التالية: 1-معرفة كلمة الوسطية من حيث الاصطلاح اللغوي والثرعي. r- معرفة سمة الوسطية في العقيدة الإسلامية. r-معرفة موقف المجتمع السعودي خاصة العلماء من وسطية العقبدة الإسلامية. ع- تشجيع المجتمع الإسلامي الآخر من البلدان المسلمة على التمسك بهذا المنهج القوبم. ثالثا: منهجية البحث: يعتمد هذا البحث على المنهج الوصفي والاستقرائي. المبحث الأول

\section{مفهوم الوسطية والعقيدة الإسلامية}

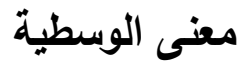

الوسطية من الوَسَط أو من الوَسنطُ، ومعنى الوسط في اللغة: الوسط من كل شيء أعدله(9)، ووسط الهُ الثيء هو ما بين طرفيه وهو منه "المعتدل من كل شيء"، وأمة وسطا أي عدولا وخيارا، والرجل من من وهو وسط قومه: من خيارهم.(·') و"قيل في صفة النبي صلى الله عليه وسلم: أنه كان أوسط قومه: أي من خيارهم والعرب تصف الفاضل النَّسَب بأنه من أوسط قومه،، وهذا يعرف حقيقته أهل اللغة، لأن العرب تستعمل التمثيل كثيراً، فتُمنل

(9) الفارابي، أبو نصر إسماعيل، الصحاح تاج اللغة وصحاح العربية،

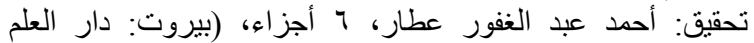

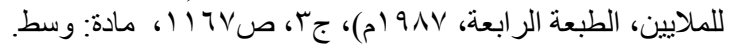

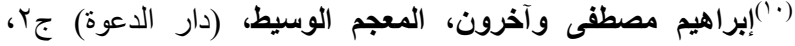

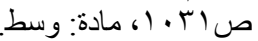


ومن استعماله في الأجسام، كأن تقول عقد العسل أي اشتذ، وعن) وعقد الحبل والخيط. ومن مجموع ما تقدم نعلم أن العقيدة تطلق، فيراد منها الأمر الذي يعتقده الإنسان، ويعقد عليه قلبه لفيه

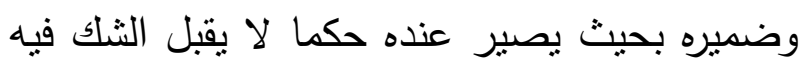
لدى معتقده، فاعتقد كذا بقلبه، أي صلار لله عقيدة.

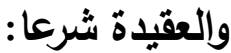

ما يدين به الإنسان ربه، والعقيدة الإسلامية مجموعة

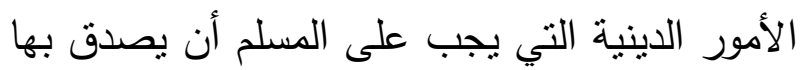

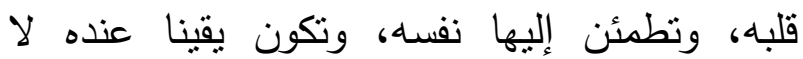
يمازجه شك، ولا يخالطه ريب.(T) المبحث الثاني

الوسطية في العقيدة الإسلامية ومنهج المجتمع السعودي في تلقي العقيدة الوسطية في العقيدة الإسلامية: تتجلى وسطية الإسلام في العقيدة بأروع صورها،

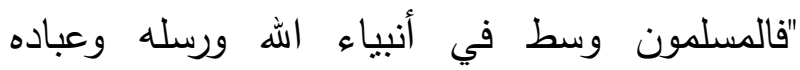

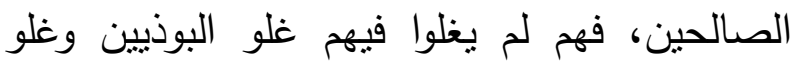

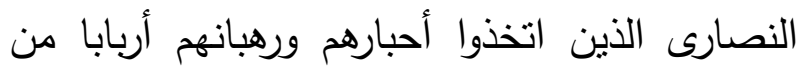

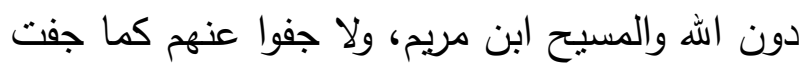

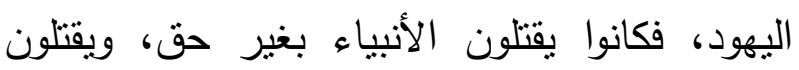

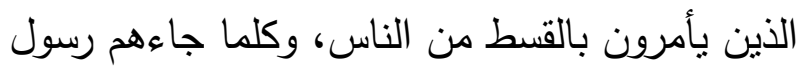

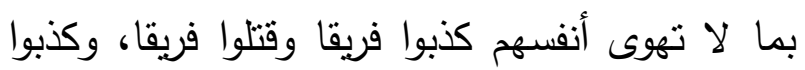

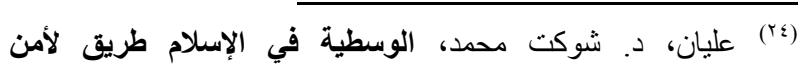

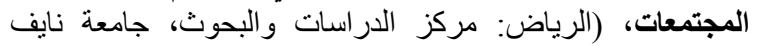

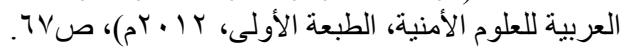

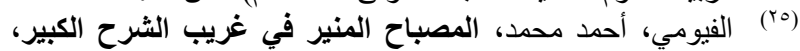
تصحيح: مصطفى السقا، (بيروت: المكتبة العلمية، بدون الطبية الطبرحة الكبر،

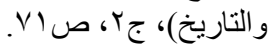

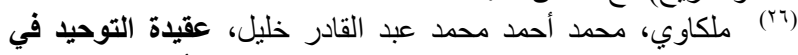
القرآن الكريم، (الرياض: دار ابن تيمية، الطبعة الأولى، بلدة التوحداد)،

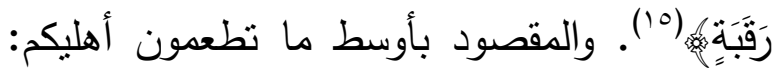
أي أقصده وأغلبه لا أعلاه ولا أدناه.

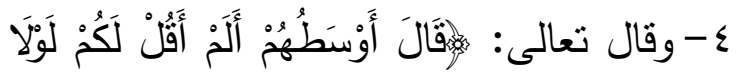

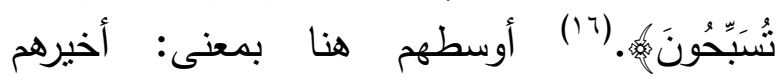

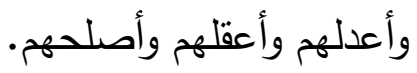

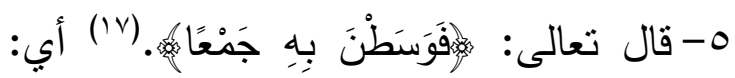

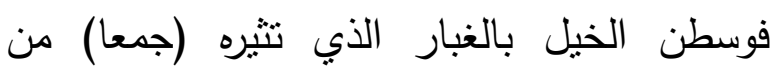
العدو، أي صرن وسطه. (^) الغيل

\section{مفهوم العقيدة الإسلامية المية}

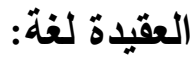
العقيدة مأخوذة من العقد على وزن فعيلة، وهو نقيض الحل، يقال: عقد الثيء يعقده عقدا، وانعقد وتعقد، والمعاقد هي مواضع العقد، وعقدت الحبل ئل

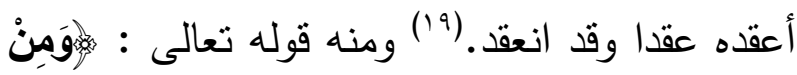

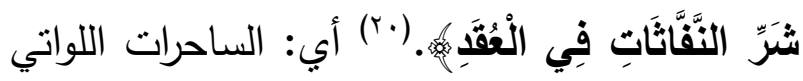
يعقدن الخيوط وينفتن فيها، وقد استعمل العقد في

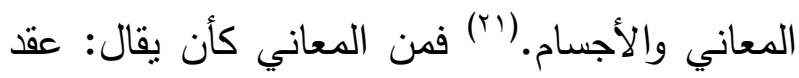
العهد واليمين، أي أكدهما، ومنه قوله تعالى:

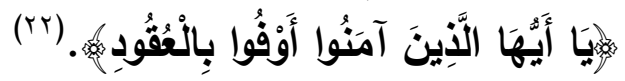

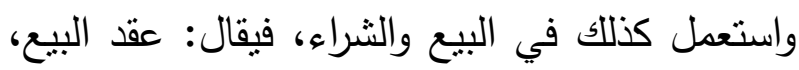
وعقد النكاح، ومنه اعتقد الأمر أي صدقه، واعتقدت كذا عقدت عليه القلب والضمير ، حتى قيل: العقيدة الضئ هي ما يدين الإنسان به. (r)

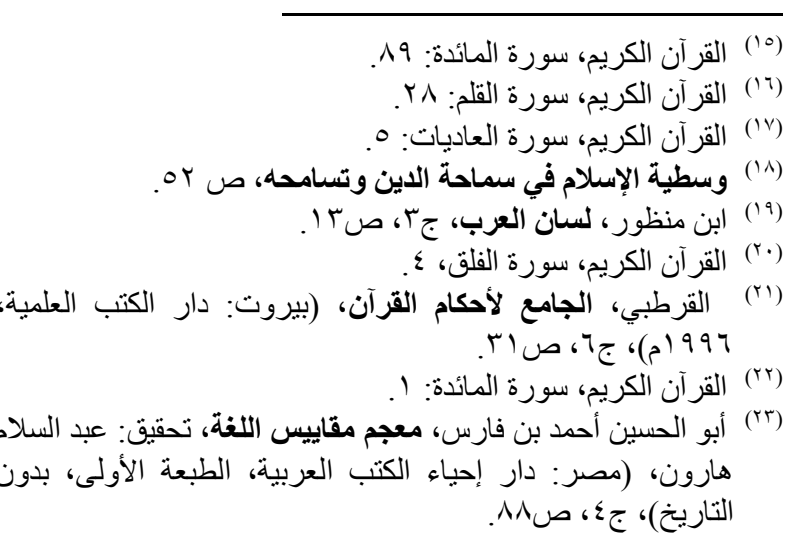


الكتاب والسنة والإجماع (يعني إجماع السلف الصالح-رضوان الله عليهم-)، فيستمد علماء السلف عقائدهم من هذه المصادر الثناثة، وأن مذهبهم

$$
\text { "مذهب قديم" قدم الإسلام نفسه (·r). }
$$

يقول شيخ الإسلام مبينا منهج السلف في نلقي العقيدة: "أما الاعتقاد فلا يؤخذ عني، ولا عمن هو مو أكبر مني، بل يؤخذ عن الله ورسوله -صلى الله عليه وسلم-، وما أجمع عليه سلف الأمة" ('rا"). ولا شك أن هذا المنهج هو منهج الاعتدال والوسطية الذي يتسم به المجتمع السعودي بشكل عام في تلقي عقيدتهم من القرآن والسنة وإجماع السلف الصالحين من الصحابة والتابعين ومن تبعهم بإحسان إلى يوم الدين.

\section{المبحث الثالث}

مظاهر وسطية العقيدة في المجتمع السعودي

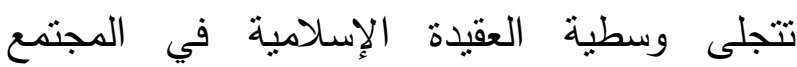
السعودي، خاصة علماء السعودية يهتمون الوسطية اهتماما بالغا في هذا الجانب، وهم يعتقدون بكل ماء جاء في القرآن والسنة، وذللك بعيدا عن الغلو والتطرف والنشدد. أولا: الوسطية في الإيمان بالله تعالى: معنى الإيمان بالله تعالى: "هو التصديق الجازم من صميم القلب بوجود ذاته لالهان تعالى الذي لم يسبق بضد ولم يعقب به، هو الأول فليس قبله شيء، والآخر فليس بعده شيء، والظئ والظاهر

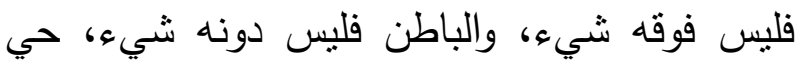

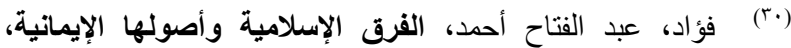

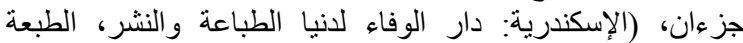

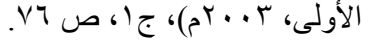

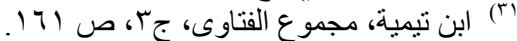

على ربهم، بل المؤمنون المسلمون آمنوا برسل الله

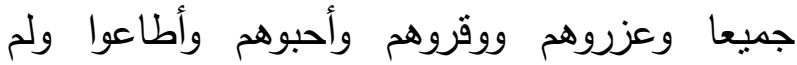

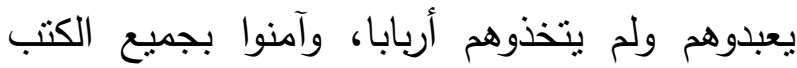
المنزلة على الرسل والأنبياء، فكان ذلك وسطية

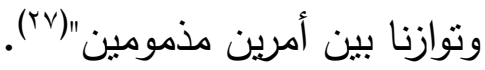
وإن الباحث المتأمل في العقائد الإسلامية الصحيحة يجد أنها وسط بين من يتبعون الخرافة والأسطورة مهملين العقل الصحيح والدليل البرهاني مصدقين بكل شيء يصل إليهم تقليدا واتباعا أعمى، وبين الماديين الذين ينكرون كل شيء وراء الحس ولا

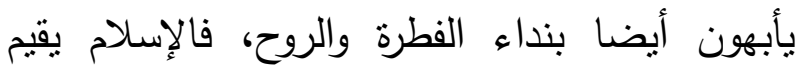
عقائده على براهين مقنعة وأدلة ساطعة، يقول الله

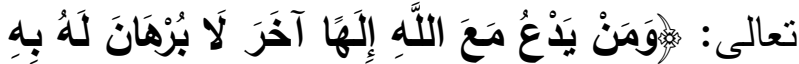

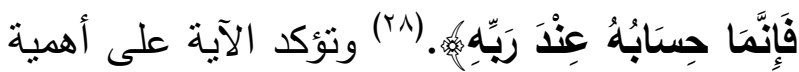
الاليل والبرهان ويطالب به على قضايا قد ثبت لثابه فسادها وبطلانها، فمن المعلوم أنه لا برهان على

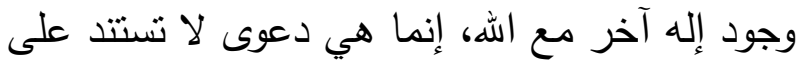
أساس، وجاء في كتب السنة أنه عندما نوفي إبراهيم ابن نبينا محمد -صلى الله عليه وسلم- كسفت

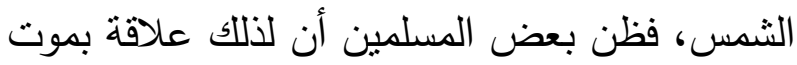

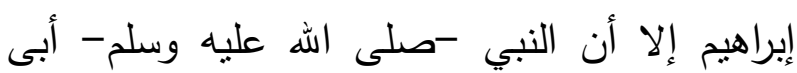
ذللك الفهم ونهى المسلمين عن مثل ذلك الاعتقاد التها

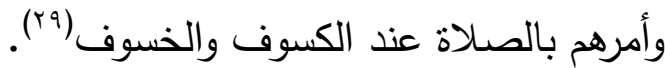
منهج المجتمع السعودي في تلقي العقيدة وتقريرها: منهج المجتمع السعودي في تلقي العقيدة وتقريرها هو المنهج السلفي الذي يقوم على أصول ثلاثة:

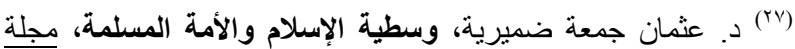

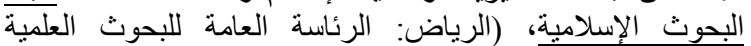

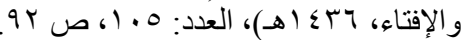

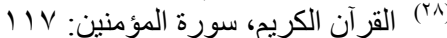

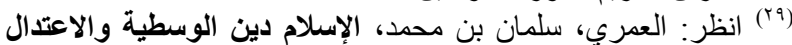
على مدى الأزمان، (سلمان محمد العمري، الطبعة الأولى، الألى الطئ . 
باله تعالى، فموققهم من الإيمان باله تعالى موقف وسط، لا تفريط فيه ولا إفراط.

يقول الإمام ابن تيمية كرحمه الله تعالى - مخبرا عن منهج السلف كرضوان الله عليهم أجمعين وسط في باب صفات الله سبحانه وتعالى: بين أهل التعطيل الجهمية، وبين أهل التمثيل المثبهة. وهم وسط في باب أفعال الله تعالى: بين القدرية والجبرية. وفي باب وعيد الله: بين المرجئة وبين الوعيدية من القدرية وغيرهم. وفي باب الإيمان والدين: بين الحرورية والمعتزلة، وبين المرجئة والجهمية"(؟َ). وكما نلاحظ في علماء المجتمع السعودي أنهم يعظمون أمر التوحيد ويضعونه فوق كل شيء ويعملون على قمع الثرك من جذوره وأنواعه من المجتمع البشري ويدعون إلى ذللك، يقول الإمام محمد بن عبد الوهاب في كتابه (ثلاثة الأصول وأدلتها): "وأعظم ما أمر الله به: التوحيد؛ وهو إفراد الله بالعبادة، وأعظم ما نهى عنه: الشرك؛ وهو دعوة

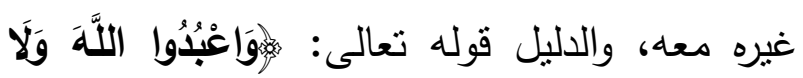

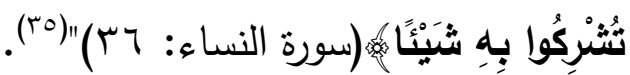
ثانيا: الوسطية في الإيمان بالرسل - عليهم السلام - (المام

\section{معنى الإيمان بالرسل:}

"هو التصديث الجازم بأن الله تعالى بعث في كل أمة رسولا منهم يدعوهم إلى عبادة الله وحده والكفر بما يعبد من دونه، وأن جميعهم صادقون مصدقون

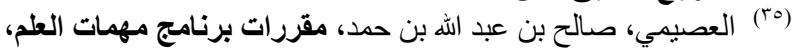

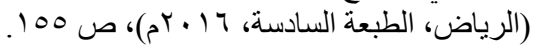

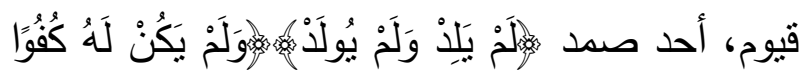

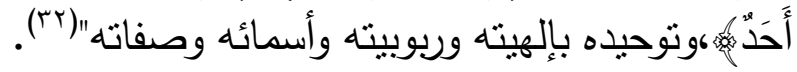
الوسطية في الإيمان بالله: يتميز المجتمع السعودي بالوسطية في الإيمان باله سبحانه وتعالى، فهم يؤمنون بالله عز وجل كما أخبر الله تعالى عن نفسه وكما بينه الرسول محمد صلى الله عليه وسلم من غير تحريف ولا تعطيل. يقول الإمام ابن تيمية كحمه الله تعالى - في كتابه "العقيدة الواسطية- عن الإيمان باله تعالى: "الإيمان بما وصف به نفسه في كتابه، وبما وصفه به رسوله محمد كسلى الله عليه وسلم-، من غير تحريف ولا تعطيل، ومن غير تكييف ولا تمثيل؛ بل يؤمنون بأن

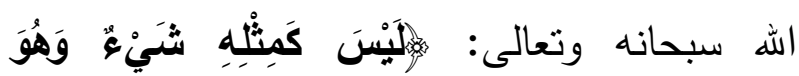

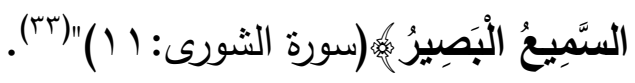
موقف المجتمع السعودي من الوسطية في الإيمان بالله: فالمجتمع السعودي يدعو إلى الإيمان باله تعالى في أنفسهم وفي غيرهم كما ورد ذلك في القرآن والسنة وكما مارسه السلف الصالحين من الصحابة رضوان الله تعالى عليهم أجمعين ومن تبعهم بإحسان إلى يوم الدين. فيسعون إلى البعد عن الغلو والتقصير في إثبات صفات الله تعالى وأفعاله وما بتعلق بالإيمان

الحكيمي، حافظ بن أحمد، أعلام السنة المنثورة لاعتثقاد الطائفة

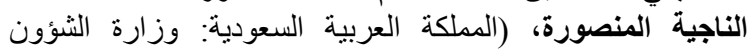

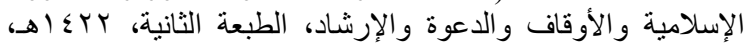

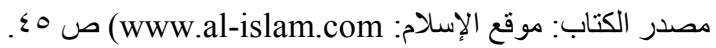

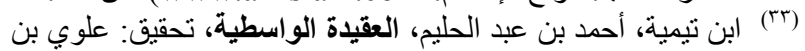
عبد القادر السقاف، (المملكة العربية السعودية: الدرر السنية، الطية، الطبعة الطبة

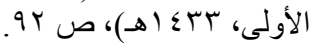




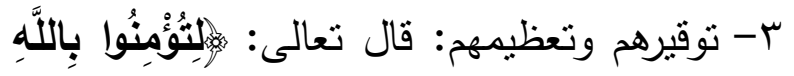

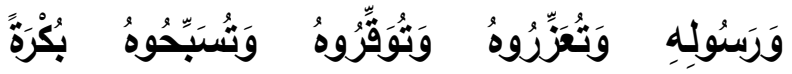
وَأَصِيلًا وغير واحد: "تعظموه وتوقروه من التوقير وهو

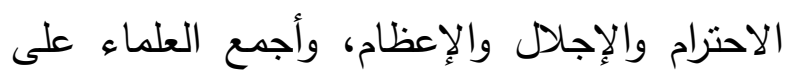
أن من انتقص نبيا من الأنبياء فقد كفر". ع- وجوب العمل بشرائعهم: وذلك في حق كل أمة الائاه لنبيها، ولا يخفى أن ذلك قبل بعثة نبينا صلى الله عليه وسلم التي نسخت شريعته كل شريعة.

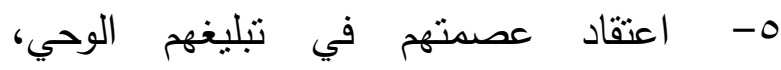

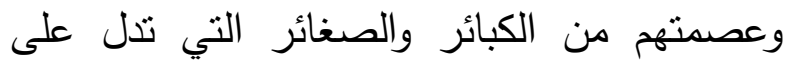
خسة الطبع وسفول الهمة"(•؛). الوسطية في محبة الرسول -صلى الله عليه وسلمظاهرة الغلو في محبة الرسول في المجتمع

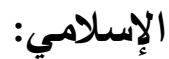

لو تطرقنا إلى النظر في بعض البلدان المسلمة

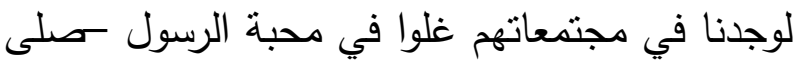
الله عليه وسلم-، وذلك منبثق عن اعتقاد هؤلاء المغالين حول الرسول - صلى اله عليه وسلم-. وهناك بعض الاعتقادات تجاه الرسول -صلى الله عليه وسلم- التي تنؤديهم إلى الوقوع في الثرك والكفر والبدعة، كالاعتقاد: 1- أن الرسول -صلى الله عليه وسلم- يعلم الغيب.

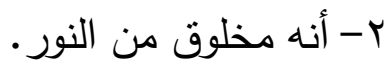

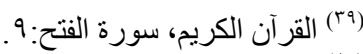
(•) انظر : الإيمان بالأنبياء والرسل حقيقته ومقتضياته، http://articles.islamweb.net/media/index.php?page=a rticle\&lang $=$ A\&id $=13386$
بارون راتثدون كرام بررة أتقياء أمناء هداة مهتدون، وبالبراهين الظاهرة والآيات الباهرة من ربهم مؤيدون، لبهرة

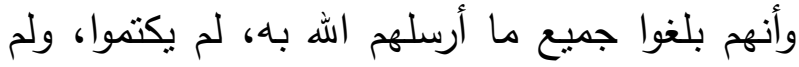
يغيروا، ولم يزيدوا فيه من عند أنفسهم حرفا ولم

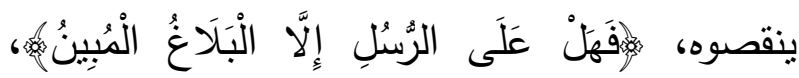

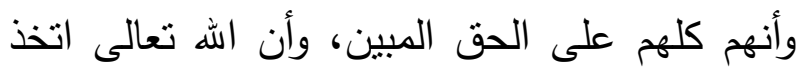
إبراهيم خليلا، واتخذ محمدا صلى الله عليه وسلم خليلا وكلم موسى تكليما، ورفع إدريس مكانا عليا، وأن عبسى عبد الله ورسوله وكلمته ألقاها إلى مريم وروح منه وأن الله فضل بعضهم على بعض ورفي ورفع بعضهم درجات" (Tr". الوسطية في الإيمان بالرسل: إن المجتمع السعودي يؤمن بالرسل -عليهم السلامحسبما جاء البيان عنهم في القرآن والسنة مفصلا ومجملا، فموققهم من الإيمان بالرسل -عليهم السلام- موقف معتدل ومنتوسط دون الإفراط والتفريط، وبتضمن إيمانهم أمورا كالتالي: 1- "التصديق بنبوتهم وبما جاءوا به من عند الله

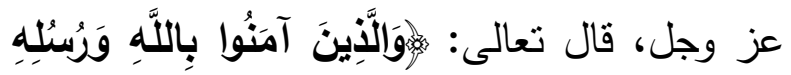

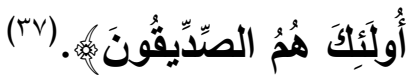
r- عدم التقريق بين أحد منهر كما قال تعالى :

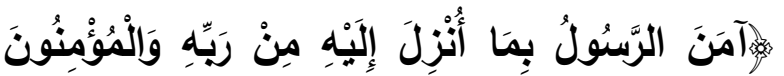

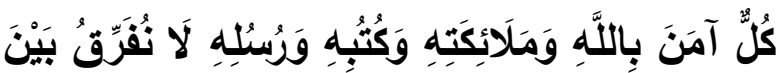

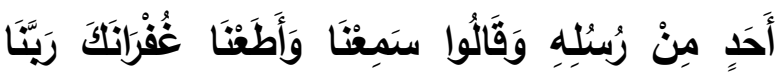

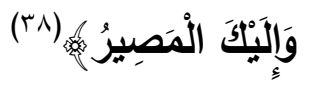

("ب) أعلام السنة المنشورة لاعتقاد الطائفة الناجية المنصورة، ص

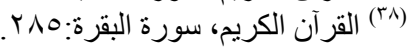


فهم لا يقولون بأن الرسول سصلى الله عليه وسلميعلم الغيب وعنده مفاتيح الخير، ولا يعتقدون أنه خُلق من النور ، ولا بيتغيثُن ولا بدعون به كما يفعل بعض المسلمين من الغلاة الصوفيين من البلدان الأخرى.

فإنهم يحبون الرسول - صلى الله عليه وسلمويوقرونه حسب توجيهات القرآن والسنة النبوية ولا يقيمون الطرق البدعية المنتشرة في كثير من البلدان الإسلامية.

من حسن حظ المجتمع السعودي أن وجد فيهم العلماء السلفيين الذين قاموا وما زالوا قائمين بحسن تربيتهم في الجانب العقدي وتتقيته من الثوائب

$$
\text { والثرك. }
$$

ثالثا: الوسطية في الإيمان بالملائكة: وتتضح وسطية في الإيمان بالملائكة، حين ندرك أن المالئكة في الإسلام ليسوا آلهة تعبد، ولا إناثا اتخذها الرحمن بنات له، يقول عبد العظيم المطعني موضحا طرفي النقيض الذي وقع فيه البشر في تصورهم للملائكة: "هنالك من عبدهم، وهناك من ظن أنهم بنات الله، وأما الفلاسفة برون أن الملائكة هم الأفلاك التي نراها في الفضاء، وبعضهم أنكر وجودها، وأما اليهود فعادوا بعضهم، ووصفوا الملائكة بأنهم يثربون ويأكلون"(r؟).

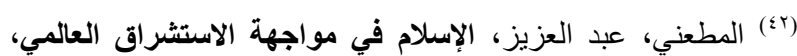

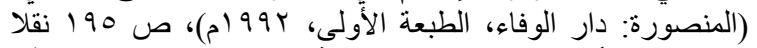

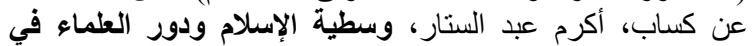

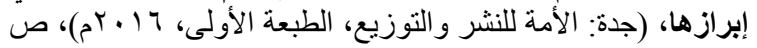

r- أنه يكثف الضر •

وما إلى ذلك من الاعتقادات الباطلة التي لا تليق بشأن الرسول -صلى الله عليه وسلم- في ضوء القرآن والسنة النبوية. ونتيجة لمثل هذه الاعتقادات الباطلة نشأ فيهم الغلو في محبة الرسول - صلى الله عليه وسلم- الخارج عن توجيهات القرآن والسنة النبوية كإطراء الرسول منل إطراء اليهود والنصارى، وإقامة العيد بمولد النبي - صلى الله عليه وسلم، والدعاء والاستخاثة به عند المصائب والحاجات. (1) موقف المجتمع السعودي من محبة الرسول-صلى الله عليه وسلم:يتميز موقف المجتمع السعودي من محبة الرسول صلى الله عليه وسلم- بالاعتدال والوسطية بين الغلو والجفاء. لقد مَنَّ الله على العرب أن أرسل فيهم مجددين للإسلام كالإمام ابن تيمية -رحمه الله تعالى-، والثيخ محمد بن عبد الوهاب كرحمه الله تعالى -، ومن سار على نهجهم من العلماء الكواكب الذين بذلوا قصارى جهودهم في محاربة البدع والثرك والخرافات من المجتمع الإسلامي وبالأخص المجتمع السعودي كالشيخ ابن باز كرحمه اللهوالثيخ ابن عثيمين كحمه الله-. فمن فضل الله وكرمه أن طهر بهم بلاد المملكة العربية السعودية من درن الثرك والبدع والطغيان. فالمجتمع السعودي لا يعتقد في الرسول محمد صلى الله عليه وسلم- ما لم يرد في القرآن والسنة. 
عن مواضعه، وإنما يؤمنون بكل ما نزل على رسل

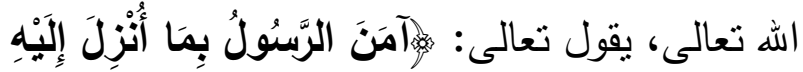

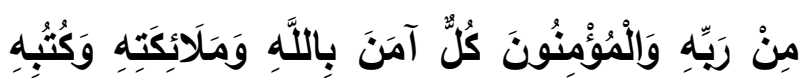

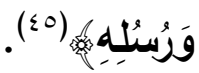
يقول الثيخ محمد بن صالح العثيمين كحمه الهه-:

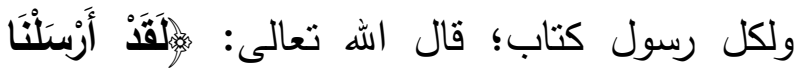

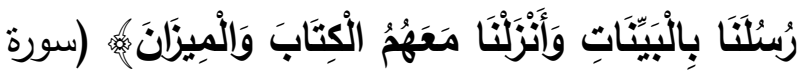
الحديد: ب0)، وهذا يدل على أن كل رسول معه كتاب، لكن لا نعرف كل الكتب، بل نعرف منها: صحف إبراهيم وموسى، التوراة الإنجيل، الزبور، القرآن؛ ستة؛ لأن صحف موسى بعضهم يقول: هي التوراة، وبعضهم يقول: غيرها، فإن كانت التوراة؛ فهي خمسة، وإن كانت غيرها؛ فهي ستة، ولكن مع ذلك نحن نؤمن بكل كتاب أنزله الله على الرسل، وإن لم نعلم به، نؤمن به إجمالا(T؛). خامسا: الوسطية في الإيمان باليوم الآخر: الإيمان باليوم الآخر معناه: "أن تصدق بكل ما بعد الموت من عذاب القبر ونعيمه، وبالبعث بعد ذلك والحساب، والميزان، والثواب والعقاب، والجنة والنار ، وبكل ما وصف الله به يوم القيامة"(2v). وأما وسطية العلماء السعوديين في الإيمان باليوم الآخر؛ فقد حاز عليها العلماء، فلم ينكروا الإيمان بهذا اليوم، ولم يؤمنوا بـه إعادة للأرواح دون

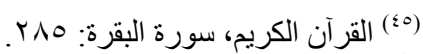

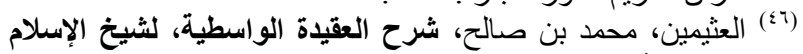

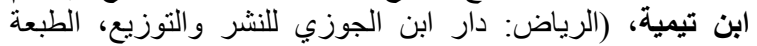

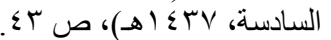

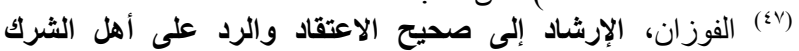

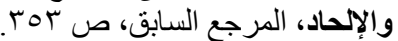

كما ذكرت التوراة المحرفة في سفر التكوين وبعض أسفارهم: "أن الملائكة لا تأكل ولا تشرب واضطرب أمرهم في هذا الثأن، واستزلهم الثيطان، وتصور التوراة بأن جبريل -عليه السلام- بأنه شيطان ــعنة الله على اليهود- يضع الغواية ويغوي الأنبياء"(ז؛). وهذه هي التصورات الباطلة دن الفلاسفة واليهود حول الملائكة، وأما الإسلام فهو وقف موقفا وسطا، فلم ينف وجود الملائكة كما نفى النافون، ولم يجعل الملائكة بنات لله كما فعل المجحفون، وإنما ألزم المؤمن أن يعتقد بكون المالأكة موجودين مخلوقين من نور، وأنهم لا يعصون الله ما أمرهم، وأنهم قائمون بوظائفهم التي أمرهم بالقيام بها. فالمجتمع السعودي خاصة العلماء منهم يؤمنون على المالئكة بكل ما ورد في القرآن والسنة، يقول الدكتور صالح الفوزان: "الإيمان بالمالائكة يتضمن: التصديق بوجودهم وأنهم عباد مكرمون، خلقهم الله لعبادته وتتفيذ أوامره ويتضمن الإيمان بأصنافهم وأوصافهم وأعمالهم التي يقومون بها حسبما ورد في الكتاب والسنة، والإيمان بفضلهم ومكانتهم عند الله عز

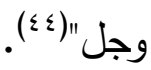
رابعا: الوسطية في الإيمان بالكتب: المجتمع السعودي العلماء منهم خاصة يققون موقف الاعتدال والوسطية مع الإيمان بالكتب، فلا ينكرون لما أنزل الله على رسله وأنبيائه، ولا يحرفون الكلم

("اء) الصلابي، علي محمد، الوسطية في القرآن الكريم، (بيروت: دار

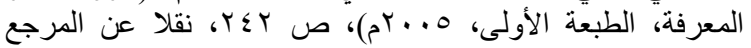
السابق.

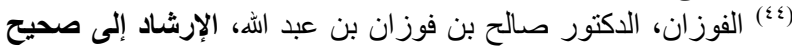

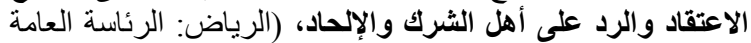

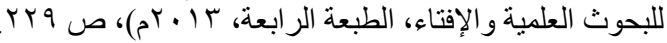




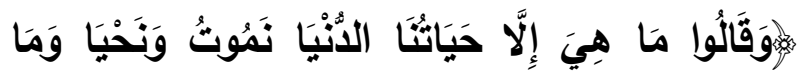

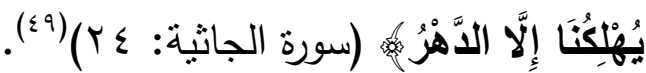
وهذا التصور عن اليوم الآخر هو التصور المتندل الذي لا إفراط فيه ولا تقريط، ويتجلى هذا التصور التصور في علماء السعودية وفي غيرهم من يهتم بالدين من أفراد المجتمع السعودي.

\section{سادسا: الوسطية في الإيمان بالقدر:}

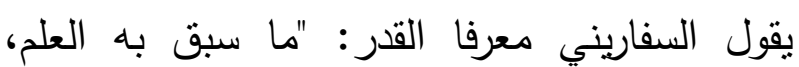
وجرى به القلم مما هو كائن إلى الأبد، وأنه سبحانه لهانه وتعالى - قدر مقادير الخالئق، وما يكون من الأثنياء قبل أن تكون في الأزل، وعلم سبحانه أنها ستقع في

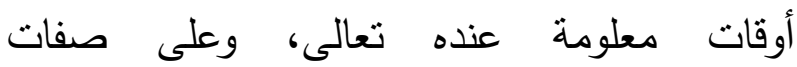
مخصوصة، فهي تقع على حسب ما قدرها"(.0. يقول الدكتور صالح الفوزان: "لا شكك أن إثبات القضاء والقدر، ووجوب الإيمان بهما وبما تضمناه من أعظم أركان الإيمان، كما قال النبي كلى الفي الهان

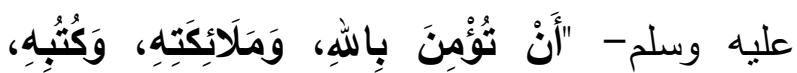

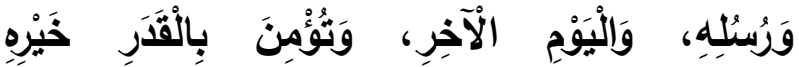

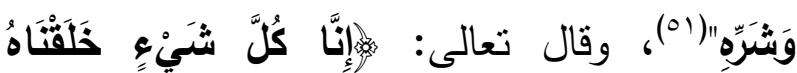

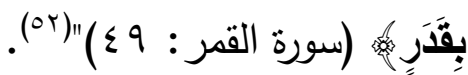
"والإيمان بالقدر يتضمن أربع درجات:

(9§) العثيمين، محمد بن صـالح، شرح العقيدة الواسطية، لشيخ الإسلام

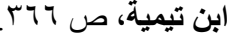
(•) السفاريني، لوامع الأنوار البهية، (دمشق: مؤسسة الخافقين ومكتبتها،

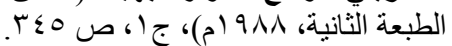

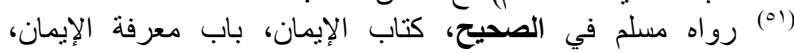

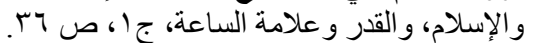

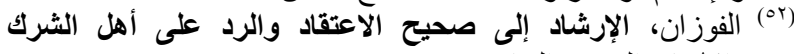

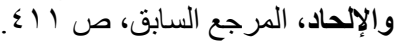

الأجساد، ولا للأجساد دون الأرواح، ولم يتخيلوا الإيمان بنعيمه وعذابه نعيما معنويا أو عذابا معنويا. يقول ابن تيمية متحدثا عن منكري اليوم الآخر

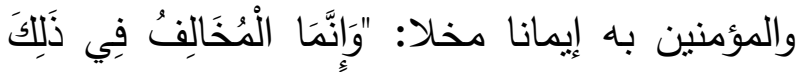

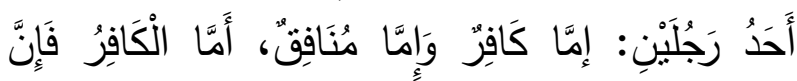

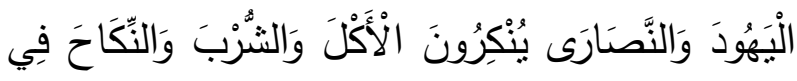

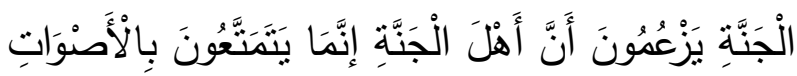

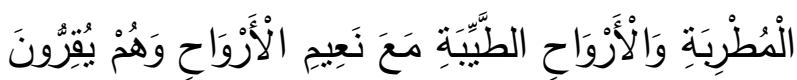

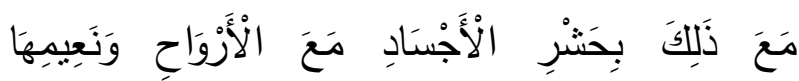

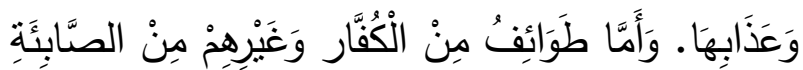

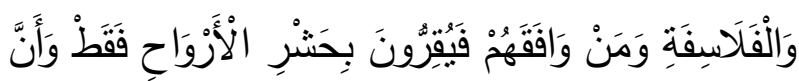

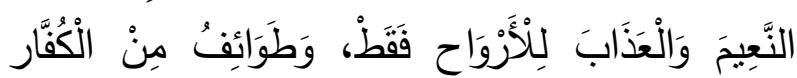

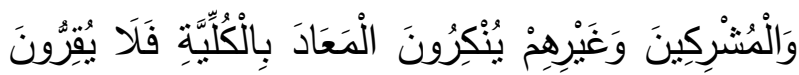

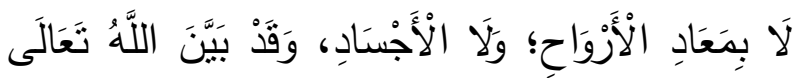

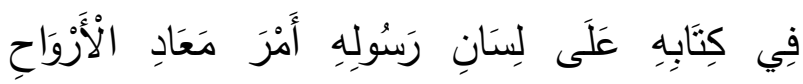

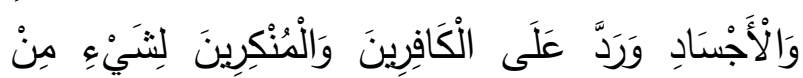

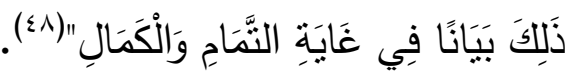
يقول الثيخ محمد بن صالح العثيمين كرحمه اله تعالى-: "كثيرا ما يقرن اله نعالى بين الإيمان به باله تعالى والإيمان باليوم الآخر ؛ الإيمان بالمبدأ والإيمان

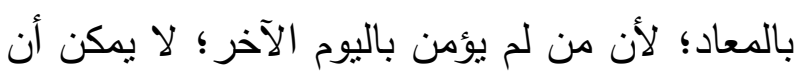

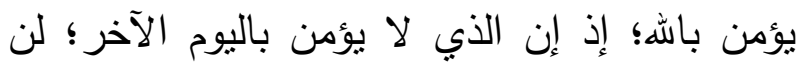
يعمل؛ لأنه لا يعمل إلا لما يرجوه من الكرامة في لإني اليوم الآخر، وما يخافه من العذاب والعقوبة؛ فإذاذا لإنا كان لا يؤمن به؛ صار كمن حكى الله عنهم: 
كما تتسب إلى الجماد، فالإنسان والجماد لا يختلفان، فكتب فلان وقتل مجازا كما يقال أثنر الثجر وتحرك

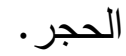

والثواب والعقاب جبر كما أن الأفعال جبر : وإذا ثبت الجبر فالتكليف أيضا كان جبرا"(هو).

يقول البغدادي: "وقال - أي الجهم - لا فعل ولا عمل لأحد غير الله تعالى وإنما تتسب الأعمال إلى المخلوقين على المجاز كما يقال زالت الثمس ودارت الرحى من غير أن تكونا فاعلتين أو مستطيعتين لما وصفتا به"(·") . إذن عند الجبرية لا حرج على العبد في فعل ما يثاء حلالا أو حراما؛ لأنه مجبور على فعله لا اختيار لله ولا إرادة. أما القدرية "فوصفوا العبد بالمقابل بالقدرة على خلق فعل نفسه، وأنه يخلق ما يريد أن يفعله"( (آ). أما أهل السنة والجماعة: "فيقررون للعبد قدرة واختيارا ومشيئة، لا يجبره على فعله أحد ، بل يفعل ما يفعله بمحض إرادته وحسب مشيئته، لكن فعله هذا وإرادته هذه داخلة في خلق الله تعالى لله، كما أنها مسبوقة بعلم الله بها ، فلا يعمل عملا إلا وقد سبق تقديره وإرادته في علم الله الأزلي، وكتبه عنده

(ه9) انظر: أبو المظفر، التبصير في الاين وتمييز الفرقة الناجية عن

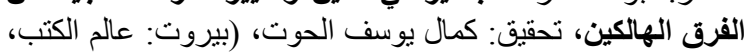

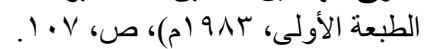

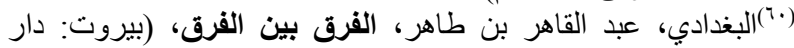

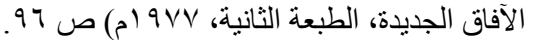

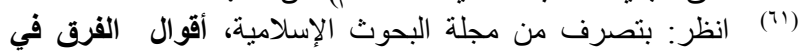

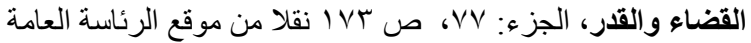
للبحوث العلمية و الإفتاء.
الأولى: الإيمان بعلم اله الأزلي بكل شيء قبل

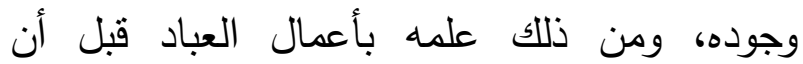
بعملوها. الثانية: الإيمان بأن الله كتب ذللك في اللوح المحفوظ. الثالثة: الإيمان بمشيئة الله الثاملة لكل حادث وقدرته التامة عليه. الرابعة: الإيمان بايجاد الله لكل المخلوقات، وأنه الخالق وحده وما سواه مخلوق" ("ه).

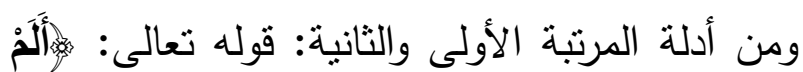

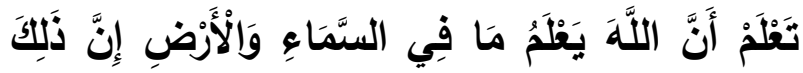

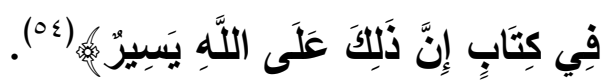

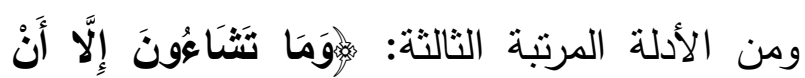

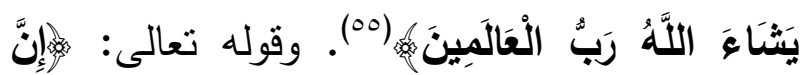

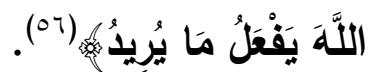

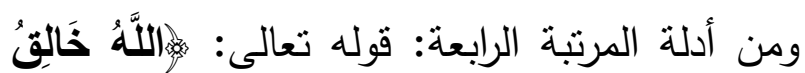

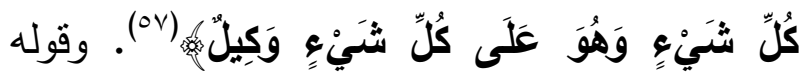

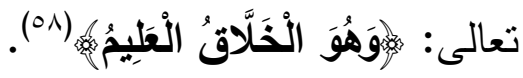
الناس منقسمون إلى ثنالثة أقسام في مسألة القدر : ا - الغلاة في الإثبات، وهم معروفون بالجبربة. r- الغلاة في النفي، وهم معروفون بالقدرية. r- المتوسطون، وهم معروفون بأهل السنة

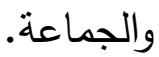
فالجبرية يرون: "أنه لا فعل لأحد غير الله تعالى، والإنسان مجبور على عمله. والأعمال تتسب إليه مجازا

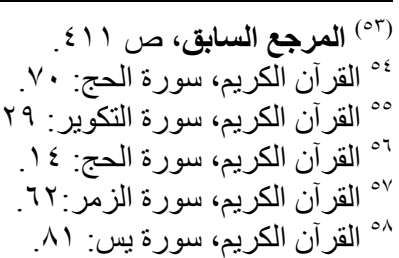




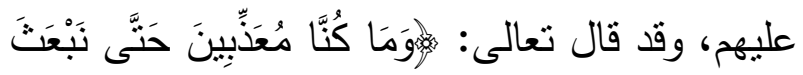

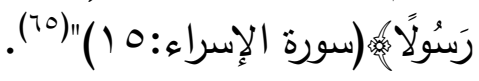
ظاهرة التكفير في المجتمع الإسدلامي: لقد كانت بداية ظاهرة التكفير في عهد سيدنا علي - رهي الاسدية رضي الله تعالى عنه- وازدادت هذه الظاهرة بعد ذللك يوما بعد يوم حتى وجدنا المسلم يكفر المسلم بأي مبرر خفيفا كان أو شديدا. وترتبت على ذلك آثارا سيئة في المجتمع الإسلامي، أثدها: افتراق المسلمين إلى فرتب على عديدة ومقاتلة بعضهم بعضا. فمثنا: أزارقة الخوارج طائفة ترمي إلى فئي الناس بالكفر إذا قصروا في واجب، أو فعلوا محرما. وما زلنا نرى كثثيرا من الناس يسارعون إلى التكفير بمثل ذلك وينصبون أنفسهم في عداوة غيرهم الذين

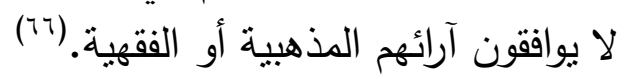

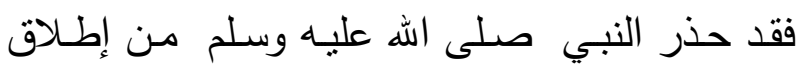
لفظ الكفر على أي مسلم، وبيّين عاقبة هذا التكفير

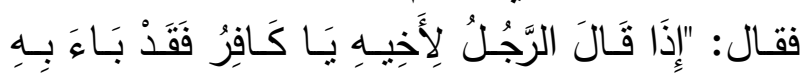

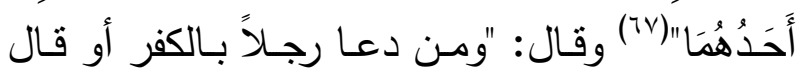

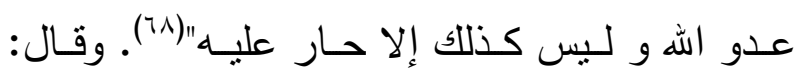
"ومن رمى مؤمناً بكفر فهو كقتله"(79) . موقف المجتمع السعودي من التكفير:

(10) الأشقر، عمر سليمان، العقيدة في الله، (الأردن: دار النفائس للنشر

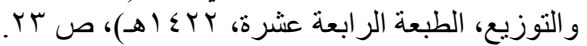

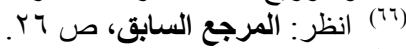

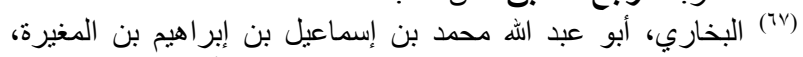

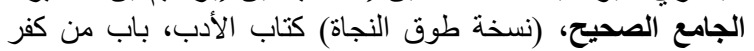

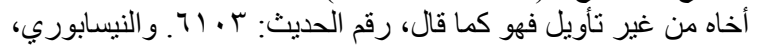

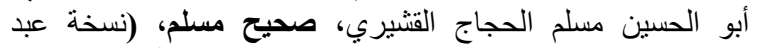
الباقي) كتاب الإيمان، باب بيان حال إيمان من قال لأخيه المسلم يا لواليا

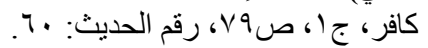

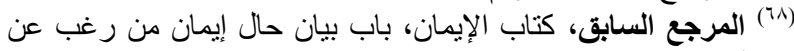

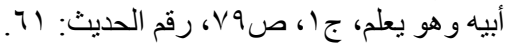

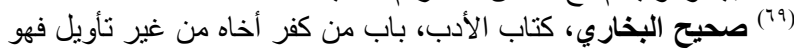

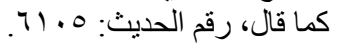

في كتابه الذي جرى بما كان ويكون إلى قيام الساعة" (rT).

وقد بين ابن بطة أن الكلام في القدر على وجهين: "أحدهما: يحرم التفكر فيه، والمسألة عنه، والمناظرة عليه، وهو يتمنل في مقابلة أفعال الله وأقداره والاعتراض عليها بكيف؟ ولم؟ وما السبب؟ وقياس أفعاله سبحانه بأفعال عباده، وشبه من يروم الاطلاع

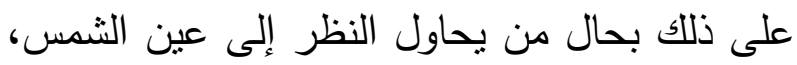
فكلما ازداد فيها نظرا ازداد تحيرا والآخر : بحل يجب علمه، ومعرفته، والإيمان به، والتصديق التهرد

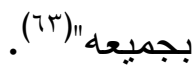
وقد أعلن ابن القيم: "أن ما يجب معرفته في هذه

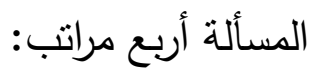

1 - علم الرب سبحانه بالأثياء قبل كونها.

r- كتابته لها قبل كونها في اللوح المحفوظ.

$$
\text { ع- خ- مشبئته لها. }
$$

فعلماء المجتمع السعودي يتسم موقفهم في مسألة القدر بالوسطية، مذهبهم وسط بين الغالية في إثبات حرية الإرادة المطلقة، وبين الغلاة في نفيها بحجة ولهة

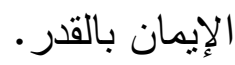

\section{سابعا: الوسطية في التكفير: الكافر عند الله:}

"الذي بلغته الدعوة الإسلامية ورفضها عن علم كافر الهر مخلد في نار جهنم، لا حجة له يوم القيامة. أما الذين لم يبلغهم الإسلام لسبب من الأسباب كأن بعدت ديارهم، أو فقدوا السمع والبصر، أو بلغهم الإسلام وهم كبار لا يعقلون، فهؤلاء لا يعذبون في وهي

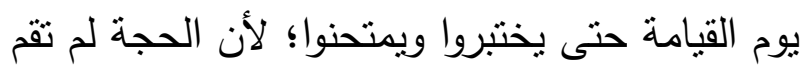

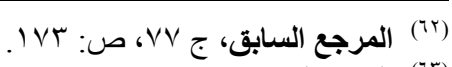

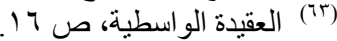

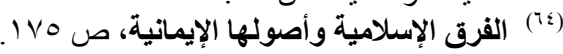


وقال شيخ الإسلام كذلك فيمَن قال ببعض مقالات

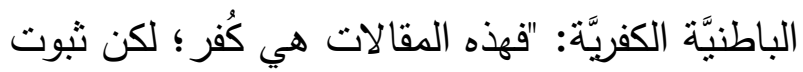
التكفير في حقِّ الثخص المعيَّن، موقوفت على قيام

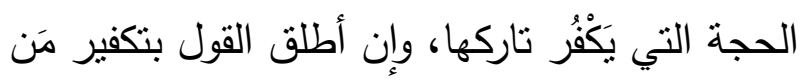

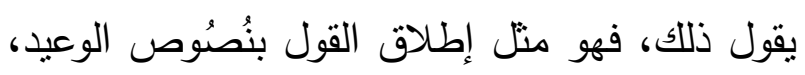

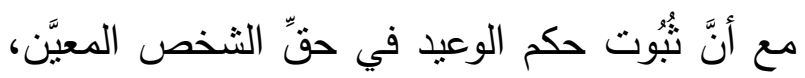

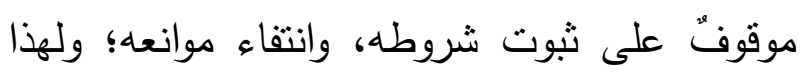

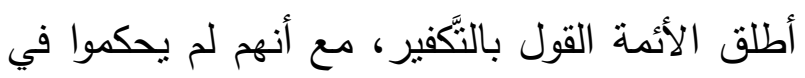
عين كلِّ قائلٍ بِحُكم الكفار ".(Vr) شروط التكفير: إذا جاءت مسألة التكفير فلا بد من توفر شروط

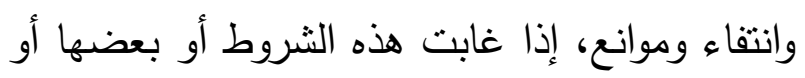

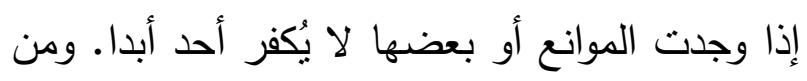

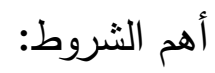
1- أن يكون عالماً بمخالفته التي أوجبت أن يكون

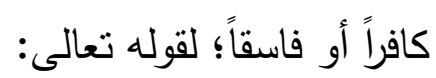

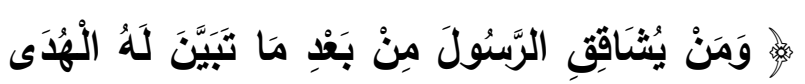

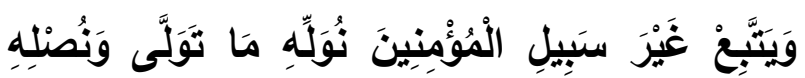

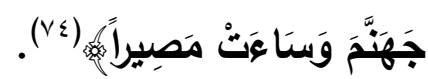

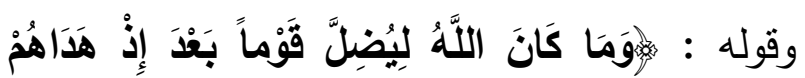

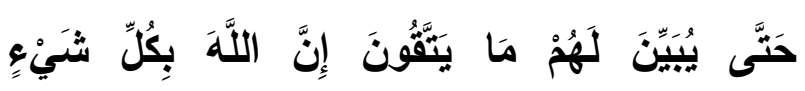

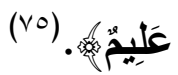
ولهذا قال أهل العلم: لا يكفر جاحد الفرائض إذا كان r- حديث عهذ بإسلام حتى يُبيَّنَ له.

(vr) http://www.alukah.net/sharia/0/4037/\#ixzz4a3pMo3Mr

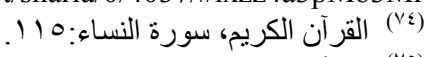

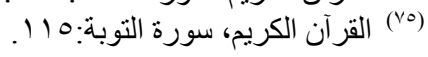

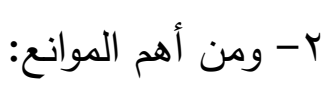

موقف علماء ودعاة المجتمع السعودي من التكفير هو موقف أهل السنة والجماعة الذي يمناز بالوسطية مودئ بين الغلو والجفاء. وهم يرون أن الذي ينزك ما ألزمه الله به من اهن

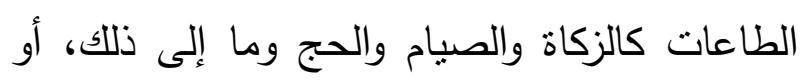

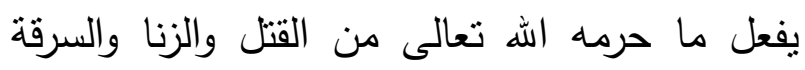
والكنب والغيبة وشرب الخمر وما إلى ذلك، قد يشوه وجه إيمانه وينقصه، لكنه لا يخرج عن ملة الإسلام إذ لم يكن جاحدا للإسلام ومستحلا لما نهاه ومحرما

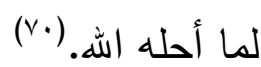

وهناك نصوص قرآنية وأحاديث نبوية تشير إلى أن المسلم لا يكفر بفعله للذنوب، ولا بتركه للواجبات، بل ينقص ذلك من إيمانه، ويكون أمره إلى الله تعالى، إذا شاء غفر له، وإن شاء حاسبه وعذبه.

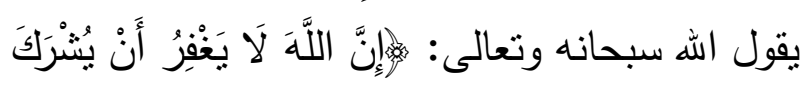

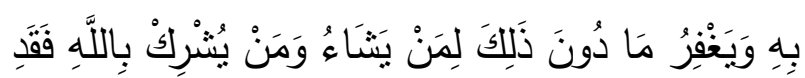

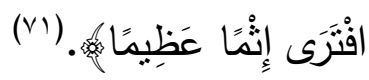
قال شيخ الإسلام ابن تيميَّة - رحمه الله -: "إنَّ

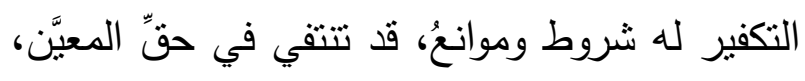

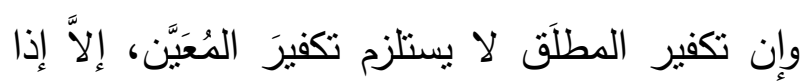

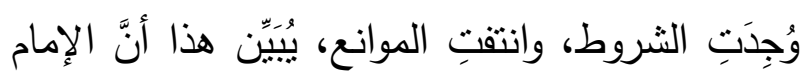

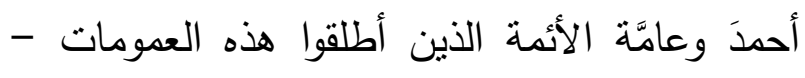
أي: مَن قال أو فعل كذا، فقد كفر - لم يُكَفِّروا أكثر الَّر

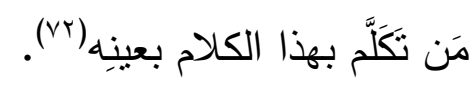




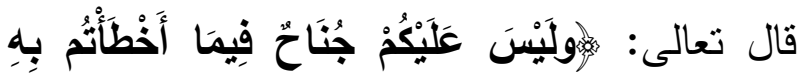

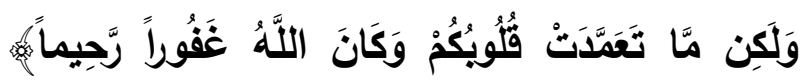

$$
\text { (سورة الأحزاب:0). }
$$

يقول ابن تيمية رحمه الله : "فالإمام أحمد رضي الله تعالى عنه ترحم عليهم (يعني الخلفاء الذين نأثروا

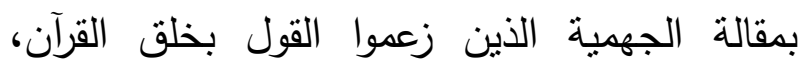

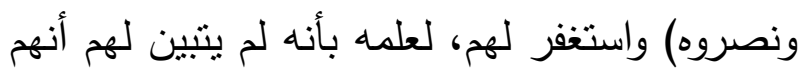
مكذبون للرسول، ولا جاحدون لما جاء به، ولكن

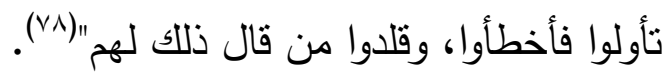
ويقول رحمه الله: "وأما التكفير فالصواب أن من فن فلن اجتهد من أمة محمد صلى الله عليه وسلم وقصد الحق فأخطأ لم يكفر ، بل يغفر له خطؤه، ومن تبين

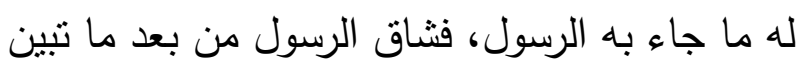

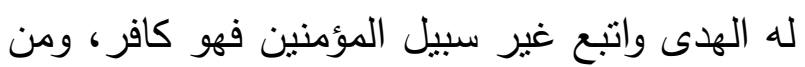
اتبع هواه وقصر في طلب الحق وتكلم بلا علم فهو عاص مذنب، ثم قد يكون فاسقاً. وقد يكون له له حسنات ترجح على سيئاته"(va). المبحث الرابع

موقف علماء السعودية من الدفاع عن العقيدة الإسلامية:

لقد أكرم الله تعالى ديننا دين الإسلام برجال

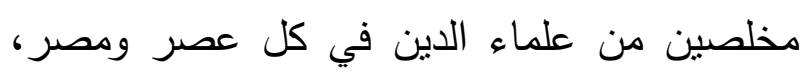
الذين دافعوا عن الإسلام وتعاليمه دفاعا قويا، وبذلوا

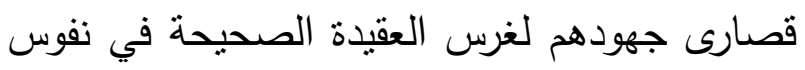

أ- أن يقع ما يوجب الكفر أو الفسق بغير إرادة

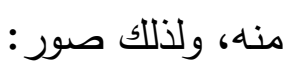
منها : أن يكره على ذللك، فيفعله لداعي الإكراه، لا

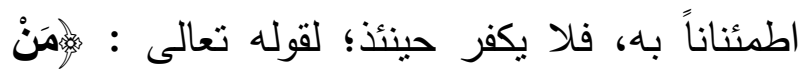

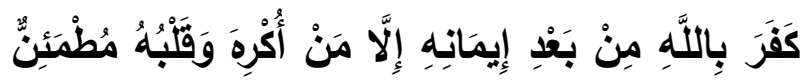

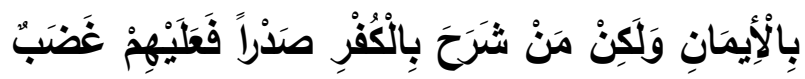

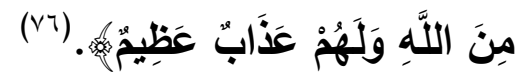

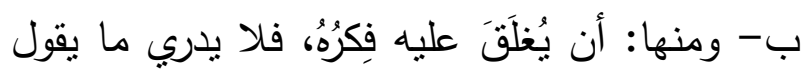
لثدة فرح أو حزن أو خوف أو نحو ذلك. ودليله ما ثبت في صحيح مسلم، عن أنس بن مالك رضي الله عنه قال : قال رسول الله صلى الله عليه

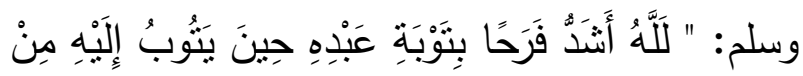

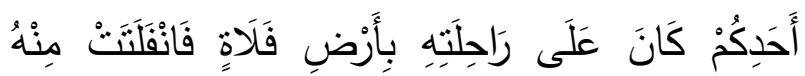

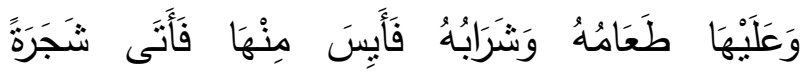

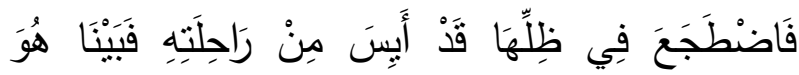

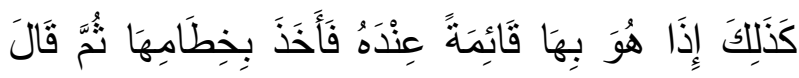

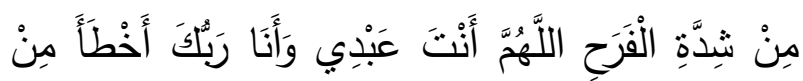

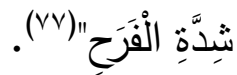

ج- ومنها أن يكون متأولا : يعني أن تكون عنده

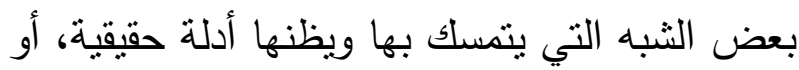
يكون لم يسنطع فهم الحجة الثرعية على وجهها، فالتكفير لا يكون إلا بتحقق تعدد المخالفة وارتفاع الجهالة.

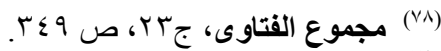

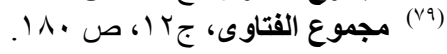

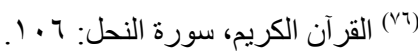

$$
\begin{aligned}
& \text { (VV) }
\end{aligned}
$$

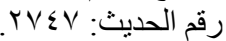


التي لعبت دورا كبيرا في تصحيح المفاهيم الخاطئة

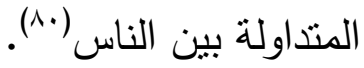
وقد سار على نهجه كثير من علماء السعودية وغير السعودية، وممن أسهم في العقيدة في العصر الراهن الثيخ عبد العزيز بن عبد الله بن عبد الرحمن بن

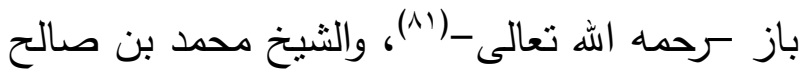
العثيمين كرحمه الله تعالى _(ז^)، والثيخ عبد العزيز بن عبد الله بن محمد آل الشيخ -حفظه الهـ-(ז^)، والدكتور صالح بن فوزان بن عبد الله الفوزان-حفظه

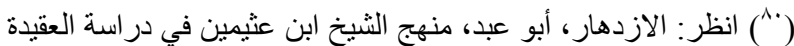

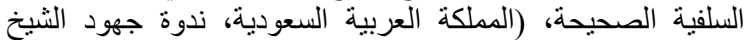

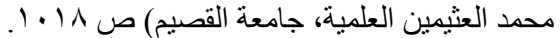

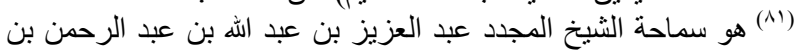

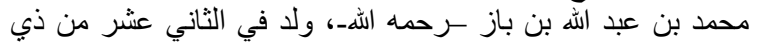

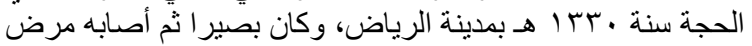

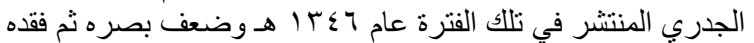

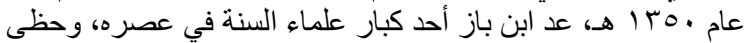

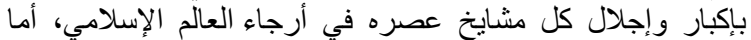

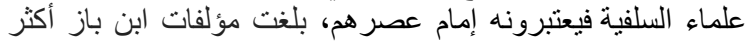

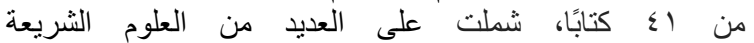

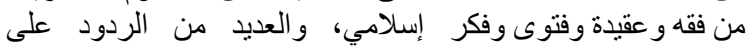

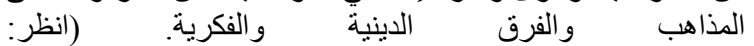
.https://saaid.net/Warathah/1/binbaz.htm

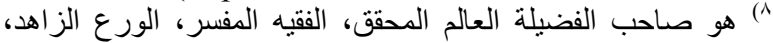

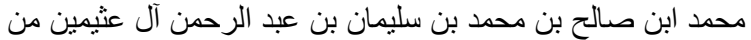

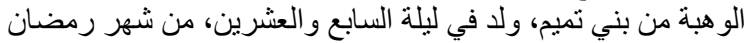

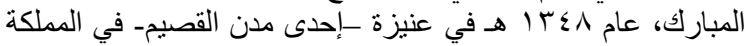

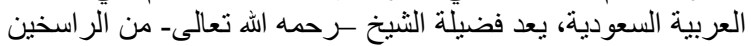

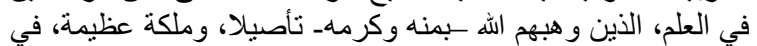

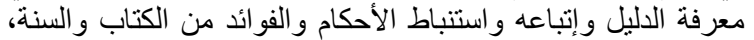

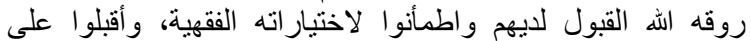

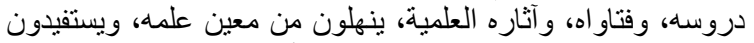

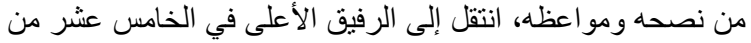

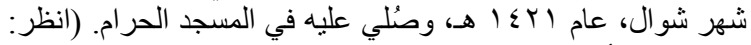

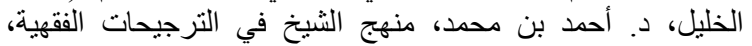

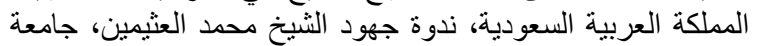

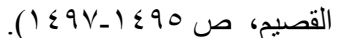

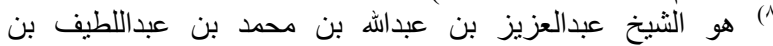

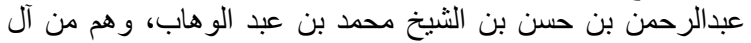

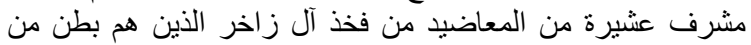

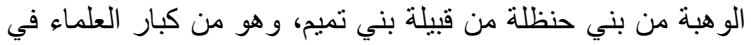

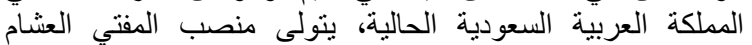

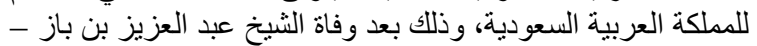

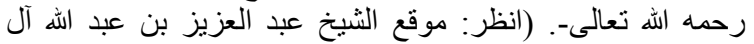

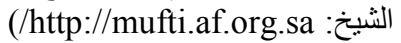

الناس أجمعين، وحاربوا البدعة والثرك وأبطلوا حجج الباطلين، وذلك عن طريق منهجهم المستقيم منهج العدل والقويم، فإن هؤلاء العلماء لم يبالوا لومة لائم

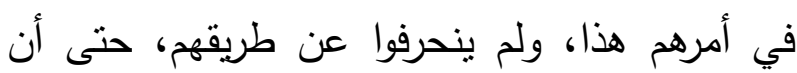

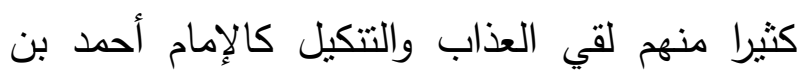
حنبل كرحمه الله تعالى - في مسالة خلق القرآن، فصبر على ذلك صبرا جميلا حتى أنار الله تعالى به السنة، وخذل به أهل البدعة، فرسخ بذلك العقيدة الصحيحة وجنبها من الانحراف. ولم يتوقف أمر الدفاع عن العقيدة الصحيحة بموت الصن

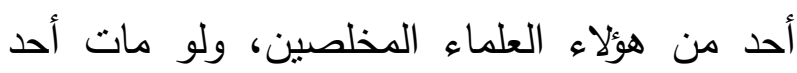
منهم قام بمهيته وحمل لواء عقيدة الإسلام أخوه الآخر بكل إخلاص وحماس، كل واحد يقف ضد أعداء الإسلام وكيدهم على قدر استطاعتهم التي وهبهم الله تعالى فيهم، فمنهم من دافع عن الإسلام

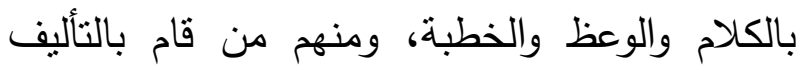
وفضح عقائد الباطلين ودحض شبهاتهم ورد على

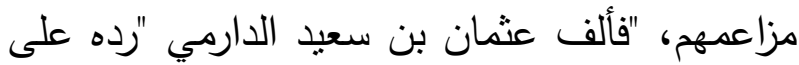
بشر المريسي"، "والرد على الجهية"، وكتب البخاري

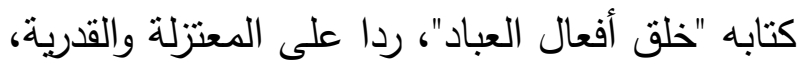
وصنف عبد العزيز الكناني كتابه "الحيدة" في الرد على "بشر المريسي"، ثم تتابع التأليف والتصنيف في نصرة مذهب السلف وذم مذاهب أهل البدع، حتى بلى بلى جاء شيخ الإسلام ابن تيمية كرحمه الله تعالى - وقام

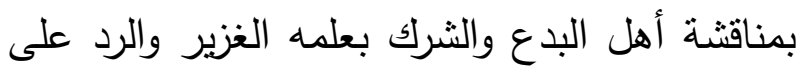

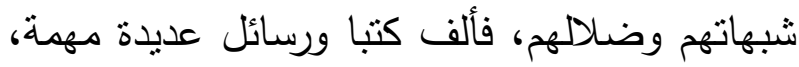


فعلماء السعودية أخذوا الوسطية والاعتدال منهجا لنشر الإسلام وتعاليمه، وهذا يظهر جليا عند المنتبع في حياتهم وخدماتهم الدعوية بأنهم تمسكوا هذا المنهج مقتدين سلفهر من الصحابة والتابعين ومن تابعهم بأحسن إلى يوم الدين. يقول الثيخ عبد العزيز بن باز كرحمه الهه تعالى عن نفسه وعن منهجه: "بحمد الله أنني منذ عرفت الحق في شبابي وأنا أدعو إلبه، وأصبر على الأذى في ذلك، ولا أحابي أحدا في ذلك، ولا أداهن، أقول الحق وأصبر على الأذى فإن قبل الحق فالحمد لله، وإن لم يقبل فالحمد لله، هذا هو الطريق الذي رسمته لنفسي فَبَلَهُ من قبله وردّه من ردّه، ما دمت على بصيرة، ما دمت على علم فيما أعتقد، فأنا أقول الحق وإن خالفني من خالفني من الناس، فلهم اجتهادهم، والله يعطي المجتهذ أجرين إن أصاب،

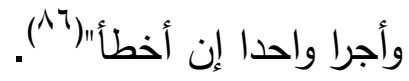
وقد اتسم منهج الوسطية والاعتدال لهؤلاء المشايخ السعوديين في مؤلفاتهم ومواقفه مع الناس والحكام، فتجلى هذا المنهج من خلال النقاط التالية التي اهتموا بها دائما:

-"استدعاء النصوص النقلية، والأدلة العقلية، ونوازل الواقع وأحداثه في نسق تكاملي للاستدلال على المسائل الاعتقادية السليمة، والرد على الفرق الضالة

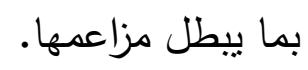
- تقديم الأدلة النقلية على الأدلة العقلية.

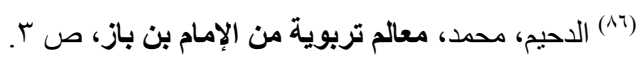

الله-(^)، وأمثالهم الذين بدافعون عن الإسـام في ساحة المعركة، وذللك عن طريق الوسطية والاعتدال دون الإفراط والتقريط، يقول الإمام ابن تيمية مبينا حالة وسطية الأمة في التوحيد: "فهم وسط في توحيد الله وأسمائه وصفاته، وفي الإيمان برسله، وكتبه، وشرائع دينه من الأمر والنهي والحلال والحرام، فأمرهم بالمعروف، ونهاهم عن المنكر، وأحل لهم الطيبات، وحرم عليهم الخبائث، لم يحرم عليهم شيئا من الطيبات كما حرم على اليهود، ولم يحل لهم شيئا من الخبائث كما استحلتها النصارى، ولم يضيق عليهم باب الطهارة والنجاسة كما ضيق على اليهود، ولم يرفع عنهم طهارة الحدث والخبث كما رفعته النصارى، فلا يوجبون الطهارة من الجنابة، ولا الوضوء للصلاة، ولا اجتتاب النجاسة في الصلاة، بل يُعد كثير من عبادهم مباشرة النجاسات من أنواع القرب والطاعات، حتى يقال في فضائل الراهب: له أربعون سنة ما مس الماء!"(^)".

(^) صالح بن فوزان بن عبد الله الفوزان هو الثيخ الدكتور في المملكة

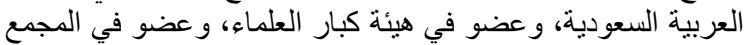

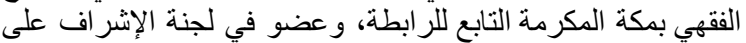

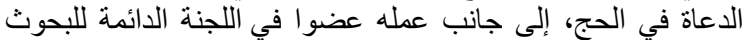

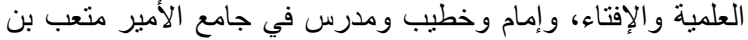

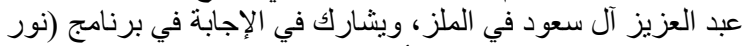

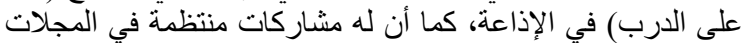

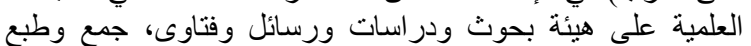

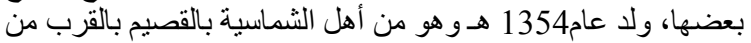

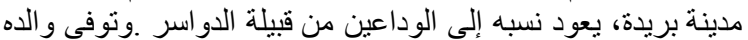

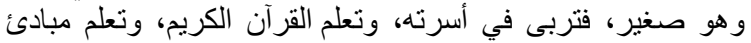

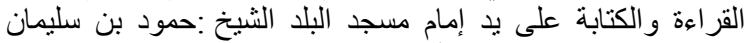
التلال، الذي تولى القضاء أخيرا في بلدة ضرية فئل في منطقة القصيم.

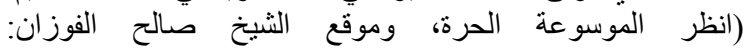
.https://www.alfawzan.af.org.sa/ar

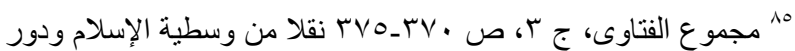

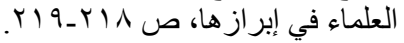


من دون التفرق بين الأنبياء والرسل في المكانة والفضل إذ لم يكن ذلك من الله تعالى. 7- لقد ظهر الغلو في المجتمع الإسلامي في محبة الرسول -صلى الله عليه وسلم- والاعتقاد فيه اعتقادا ما يعارض العقيدة الصحيحة؛ لكن من فضل الله تعالى وجهود العلماء السلفيين لقد طهَّر الله المملكة العربية السعودية من الغلو في محبة الرسول كصلى الله عليه وسلم - ومن ثم حفظهم من الثرك والبدعة. V- المجتمع السعودي في موقفه من رسول الله صلى الله عليه وسلم- يعتقد فيه حسب التوجيهات الإسلامية الصحيحة ويقدرون ويعظمونه ما يليق بشأنه في ضوء القرآن والسنة، وذلك بالاعتدال والوسطية.

^- موقف المجتمع السعودي؛ خاصة العلماء من القضاء والقدر موقف وسطي بين الإفراط والتفربط، فإنه لا يؤيد عقائد الجبرية ولا القدرية؛ بل موقفهم موقف اعتدال حسب ما ورد في القرآن والسنة. 9- لا بكفر العلماء السعوديون المسلمين بارتكاب الكبائر من الذنوب كالخوارج، ولا يكفر كل من يخالفه في الرأي في المسائل الفقهية.

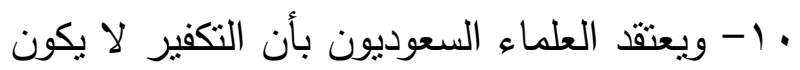
إلا بتوفر الثروط وانتفاء الموانع التي وضعتها الثربعة الإسلامية السمحة، وذلك من الجهة الخاصة

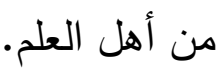
11- وبالجملة نستطيع أن نقول بأن العلماء السعوديين وبالتالي المجتمع السعودي بدافعون عن بـ بهن العقيدة الإسلامية الصحيحة دائما، وذللك عن طريق
- التقيد بمذهب أهل السنة والجماعة، في التعريف بمفهوم "التوحيد"، والتركيز على باب الأسماء والصفات لما شابه من انحراف. - تجنب الجدل والخصومات في الدين، ورفض التأويل الكلامي على اعتباره مسلك غير سليم، لا يستقيم في حق أسماء وصفات الله تعالى، ولا في حق كل القضايا العقدية التي اعتقدها سلفنا الصالح والذين التزموا فيها بمنطق التوقيف"(مv).

\section{الخاتمة}

لق توصل الباحث من خلال هذا البحث بعنوان: "وسطية العقيدة الإسلامية ومظاهرها في المجتمع السعودي" إلى نتائج عديدة، منها: 1- دينتا الإسلامي دين وسط، لا إفراط ولا تقريط فيه؛ فإنه يفضل الوسطية في كل أمر من أموره. r- لق اتسمت العقيدة الإسلامية بالوسطية

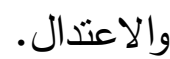

r- المجتمع السعودي خاصة العلماء اتخذوا منهج الوسطية في تلقي العقيدة الإسلامية، وتطبيقها منمسكا بمنهج الرسول سلى الله عليه وسلموالسلف الصالح-رضوان الله عليهم--. ع- مصدر التلقي للعقيدة عند السلفية وعند علماء السعودية والمجتمع السعودي هو القرآن والسنة النبوية والإجماع. 0- يؤمن المجتمع السعودي في الأنبياء والرسل كما ورد ذلك في القرآن والسنة مجملا ومفصلا، وذللك

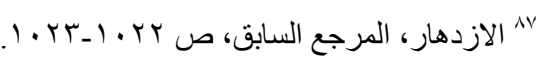


r- إقامة المؤتمرات والندوات ونشر البحوث العلمية حول الوسطية في العقيدة، وذللك في العالم الإسلامي

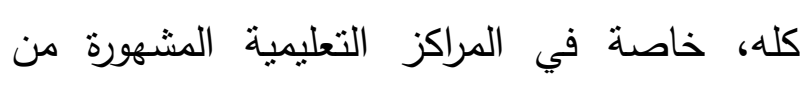

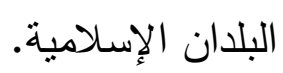

ع - إقامة المدارس والمعاهد والجامعات والكليات لتعليم ووضع المناهج الدراسية لها متسمة بالوسطية والاعتدال.

0- دعم الباحثين والكتاب في هذا المجال دعما

$$
\text { معنويا وماديا. }
$$

وصلى الله وسلم وبارك على نبينا محمد وعلى آله
منهج الوسطية والاعتدال الذي هو منهج سيد

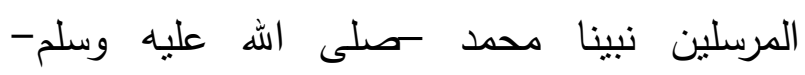

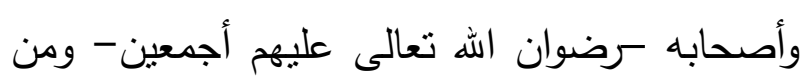
سار على نهجهم السلف الصالحون. التوصيات

يوصي الباحث إلى التوصيات التالية:

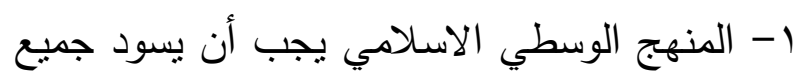

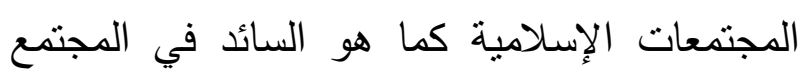

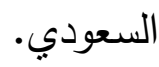
r- نشر الكتب الإسلامية التي تؤصل لوسطية

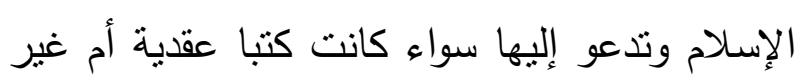
ذللك في العالم الإسلامي والدعوة إلى ذلك. 


\title{
Moderation of Islamic dogma and its manifestations in Saudi society Muhammad Amin
}

\begin{abstract}
One of the characteristics of Islam is that it is a moderate religion; neither supports excess nor supports negligence. And this manifests itself in Islamic belief, worship, rules and regulations, dealings and behavior, politics, economics and so on. As a whole, we can declare that, in every matter Islam has left the impression of moderation. This research deals with the moderation of Islamic faith and its manifestations in Saudi society as it has shown the attitudes of Saudi society towards Islamic dogma. It has been clear through this research that Islamic dogma is distinguished by moderation and Saudi society has taken this high-minded character in embracing their beliefs of Islam, dealt with Islam moderately and, accordingly, applied this doctrine in every level of their lives following the way of the Prophet -Peace and blessings be upon him- and his companions - May Allah be pleased with them- and the pious ancestors after them and their rightly followers until the day of judgment. The article is divided into three sections preceded by an introduction: the first section deals with the concept of moderation and Islamic dogma, the second section deals with moderation in Islamic dogma and the method of Saudi society in receiving their beliefs and the third one deals with the manifestations of moderated Islamic dogma in Saudi society. And finally a conclusion which gathers some findings of the article.
\end{abstract}

